\title{
Letramento e construção identitária: a emergência dos posicionamentos social e autoral em memoriais
}

\author{
Hejaine de Oliveira Fonseca*
}

\begin{abstract}
Resumo
Neste artigo discutimos o processo de construção da identidade de estudantes, no papel de leitores, em memoriais, sob a ótica do Letramento Ideológico e da Identidade Praticada. Por meio de um estudo de caso etnográfico, observou-se que o processo identitário dos estudantes de um Curso de Letras, modalidade a distância, emerge nos memoriais mediante a interface das dimensões subjetiva e coletiva, em que se evidenciam os posicionamentos social e autoral dos estudantes, por meio dos quais, eles se identificam enquanto leitores da esfera acadêmica. Os resultados apontam o caráter plástico da identidade, que varia em função do grupo de pertença do estudante. E, ainda, que as práticas leitoras do grupo pesquisado são marcadas por gestos de leitura como obrigação e prazer, cujas contradições revelam que as concepções de leitura dos estudantes em relação à academia e outros grupos sociais, como, por exemplo, a família, divergem.
\end{abstract}

Palavras-chave: Letramento. Leitura. Identidade. Memoriais.

Introdução

Aborda-se o processo de construção da identidade de estudantes, no papel de leitores, em memoriais, na perspectiva dos estudos sobre Letramento e Identidade, adotando os conceitos de Letramento ideológico (STREET, 1984, STREET; LEFSTEIN 2010; KLEIMAN, 1995, 2008a, 2008b) e de Identidade praticada (HOLLAND et al., 2010). Tais noções remetem à interação das práticas sociais, em que a leitura, concebida como atividade praticada, em contextos específicos, consolida na interação, isto é, no envolvimento do leitor com os objetos de leitura e com o Outro (autores, professores, colegas, familiares) com quem interage para construir o sentido do texto, de si mesmo ou da realidade

* Universidade Estadual de Montes Claros. 
que o cerca. Nesse sentido, as posições aqui assumidas reportam a um processo identitário que se constrói em duas dimensões: a subjetividade e a coletividade. Segundo essa perspectiva teórica, elencamos como categorias de análise, neste texto, o "Posicionamento Social" e o "Posicionamento Autoral".

Mais especificamente, objetivamos discutir como o estudante de um Curso de Letras a distância constrói sua identidade de estudante, enquanto leitor, buscando identificar como ele se apropria dos discursos que circulam na esfera acadêmica, como assume a posição de leitor universitário e se vê enquanto leitor nesse espaço.

Passa-se agora à discussão dos conceitos de letramento e identidade.

\section{Novos estudos sobre letramento}

Adota-se aqui a concepção de leitura como uma prática social engendrada na cultura do escrito e de outras tecnologias digitais. Sob esse enfoque, a leitura compreende aspectos sociais, culturais e históricos, isto é, abrange as formas de apropriação do escrito (modos de ler, gestos e finalidades de leitura) e grupos ou comunidades de leitores. Essa noção de leitura articula-se com os New Literacy Studies (Novos Estudos sobre o Letramento), abordagem relacionada à Teoria Social da leitura que enfatiza os sentidos e usos cotidianos do letramento em contextos culturais específicos.

Considerando essa visão, Barton et al. assinalam a importância do conceito de Literacy practices (práticas de letramento), enfatizando que:

práticas de letramento são os usos culturais gerais que as pessoas fazem da linguagem escrita. Dizendo de uma forma bem simples, as práticas de letramento referem-se aos diferentes usos do letramento. Entretanto, as práticas não são unidades de comportamento observáveis, uma vez que elas também envolvem valores, atitudes, sentimentos e relações sociais (ver os estudos anteriores de Street, 1993, p. 12 e Street, 1984, que discutem as práticas e eventos de

\footnotetext{
Esclarecemos que o corpus e as discussões aqui apresentadas integram uma pesquisa de Doutorado, por nós realizada, de título "Um estudo sobre a construção da identidade de estudantes, no papel de leitores, em um Curso de Letras a distância” no Programa de Pós-Graduação em Letras, Universidade Federal de Minas Gerais (DINTER-PUC-MINAS/UNIMONTES), subsidiado pela FAPEMIG, entre os anos 2010 e 2014 ..
} 
letramento). Esta noção inclui o conhecimento que as pessoas têm sobre letramento, construções de letramento e discursos de letramento, como as pessoas fazem e constroem o sentido do letramento. Essas práticas são processos internos ao indivíduo e ao mesmo tempo, processos sociais que ligam as pessoas umas às outras, incluindo conhecimentos partilhados representados em ideologias e identidades sociais. As práticas são modeladas por regras sociais que regulam o uso e a distribuição de textos, prescrevendo quem pode produzi-los e acessá-los. Elas abrangem a distinção entre os mundos individual e social. As práticas de letramento são mais úteis se compreendidas como existentes nas relações entre pessoas, dentro de grupos e comunidades do que como um conjunto de propriedades existente nos indivíduos. (BARTON et al. 2000, p.143, tradução nossa). ${ }^{2}$

Pensar as práticas de letramento sob a perspectiva sociocultural de uso da linguagem implica reconhecê-las em um âmbito que inclui não apenas as práticas de leitura como também as normas sociais, relações de poder, que regulam o acesso e as formas de apropriação do escrito. Barton et al. (2000) refletem, ainda, sobre os aspectos individuais e sociais (conhecimentos partilhados, ideologias, valores, atitudes, sentimentos) que as integram.

Prosseguindo na definição de letramento, em termos metodológicos, Street (1984, Street; Lefstein, 2010) o conceitua, advogando em favor do modelo de "letramento ideológico", enfatizando que este enfoque requer uma abordagem histórica que possibilite compreender a ideologia, cultura e tradições subjacentes às práticas atuais, que, normalmente, refletem, em suas ações, as influências escolares ou religiosas de outros momentos, além dos aspectos históricos ou das memórias das famílias relativas a outros momentos vividos. Essa reflexão fez com que optássemos por esse modelo de letramento, uma vez que, fundamentado em

2 "Literacy practices are the general cultural ways of utilizing written language which people draw upon their lives. In the simplest sense literacy practices are what people do with literacy. However practices are not observable units of behavior since they also involve values, attitudes, feelings and social relationships (see STREET 1993, p. 12, and STREET, 1984 for an early account of literacy events and practices). This includes people's awareness of literacy, constructions of literacy and discourses of literacy, how people talk about and make sense of literacy. These are processes internal to the individual: at the same time, practices are the social processes which connect people with one another, and they include shared cognitions represented in ideologies and social identities. Practices are shaped by social rules which regulate the use and distribution of texts, prescribing who may produce and have access to them. They straddle the distinction between individual and social world, and literacy practices are more usefully understood as existing in the relations between people, within groups and communities, rather than a set of properties residing in individuals". (BARTON et al., 2000, p. 143). 
uma perspectiva histórica, possibilitou-nos apreender os aspectos culturais e as relações de poder engendradas nas experiências de vida e de leitor dos sujeitos participantes deste estudo.

Na moldura teórica dos New Literacy Studies, o foco está nas práticas sociais, isto é, no espaço e nos modos de realização do letramento, em que as pessoas fazem usos concretos de escrita e de leitura, para um dado fim. As práticas de letramento são formas culturais de usar a linguagem escrita, ou seja, são os usos que as pessoas fazem do letramento (STREET, 1984; STREET; LEFSTEIN, 2010). Nelas se refletem crenças, valores, normas sociais, propósitos, atitudes e modos de agir, falar e construir sentido por parte de quem as integra. Assim, as práticas apresentam não apenas aspectos internos ao indivíduo, como ele as significa e nelas age, mas também sociais, configurando-se como processos de interação social entre as pessoas, reguladas por cognições compartilhadas, representadas em ideologias e em identidades sociais.

Sob esse enfoque, reforça-se a ideia de que as pessoas participam de comunidades discursivas distintas, que apresentam características próprias de agir, isto é, falar, avaliar, interpretar e usar a língua escrita. Esses contextos são espaços estruturados, padronizados, dentro dos quais o letramento é usado e aprendido, cujas atividades apresentam configurações particulares, formas regulares que modelam as ações das pessoas em eventos de letramento.

Partindo desse pressuposto, entende-se que o letramento apresenta características específicas dependendo do contexto ou esfera em que é praticado, isto é, o letramento acadêmico, por exemplo, apresenta características distintas do letramento praticadona educação básica. Dessas reflexões, entende-se que as práticas do letramento na esfera acadêmica, foco deste estudo, implicam a apropriação dos discursos e os diferentes usos da escrita nesse espaço. A esse respeito, Silva (2011) lembra que o acesso ao mundo da escrita dos discursos acadêmicos pressupõe a inserção dos estudantes em novas formas sociais de interação, mediadas e constituídas por novos objetos materiais, simbólicos e discursivos (gêneros discursivos, abordagens teórico-metodológicas, procedimentos científicos, normas sociais, etc.) da esfera acadêmica. Conforme a autora, esse processo mediado pela enunciação escrita requer, por parte do estudante, a construção de novos modos de agir, cognitiva, discursiva e interacionalmente, isto é, novos modos de dizer, 
de significar/interpretar, sistematizar, intervir, problematizar, de se posicionar nas práticas acadêmicas.

A respeito do ensino do letramento acadêmico, Street e Lefstein (2010) assinalam que um dos seus objetivos é possibilitar que o leitor reflita sobre os estilos e expectativas do letramento em que está inserido, levando-o a considerar as estratégias e os gêneros mais adequados às suas necessidades. E ainda que o educador reflita sobre as suas próprias experiências de escrita em vários contextos, observando questões relativas às facilidades ou dificuldades na leitura ou escrita de textos acadêmicos e a realização de atividades que explorem o letramento acadêmico (entre elas, a resenha de um livro ou artigo, a análise comparativa de textos científicos e não-científicos e a aplicação dos conceitos discutidos à escrita).

Quando se volta para as práticas de letramento acadêmico na Educação a Distância, deve-se atentar para o fato de que o estudante também passa a integrarse em práticas de escrita e leitura mediadas por um aparato tecnológico sofisticado e complexo, e ainda que o aluno nesse contexto de aprendizagem precisa desenvolver modos de agir diferenciados, entre eles, o domínio das habilidades computacionais (o uso do computador e da internet), o desenvolvimento de novas habilidades cognitivas que permitam compreender o funcionamento da internet $\mathrm{e}$ do hipertexto (que abrange o acesso a sites, participação em salas de aula virtuais, fóruns, chats, e-mails, etc), além de relações sociais necessárias à construção de sua identidade de estudante como leitor e sua inserção na comunidade acadêmica a distância. Para ilustrar essas questões que especificam as práticas do curso a distância, ${ }^{3}$ recorre-se ao depoimento da participante P03, que afirma:

agora eu tô lendo é... Paulo Freire é... meu projeto de estágio é sobre a aquisição da leitura no TCC... aí eu tô lendo todas essas leituras que fala de leitura e no site, na internet o que eu acho de interessante no site eu leio é... já li os livros de Paulo Freire já li Ofício de Mestre é... Pedagogia dos oprimidos [...] (P03 - Entrevista).

3 No decurso deste texto, para ilustrar as reflexões aqui em pauta, lançar-se-á mão de trechos de entrevistas, realizadas com as participantes da pesquisa. Esse expediente, por ora, sem nenhuma pretensão analítica, objetiva oferecer uma visada do(a) leitor(a) em relação às suas representações de leitura e/ou objetos de leitura. Esclarece-se também que o elemento P03 refere-se à forma adotada para identificar os sujeitos pesquisados, seja em situação de entrevista, memorial ou diário de leitura. 
No âmbito da pesquisa realizada, tornou-se necessário entender também o conceito de eventos de letramento ${ }^{4} \mathrm{o}$ qual remete às atividades em que normalmente há textos (escritos ou orais) que possibilitam uma discussão a respeito do assunto por eles propostos, como, por exemplo, a forma como são produzidos e usados (Como será apresentado a seguir). Conforme apontam Street e Lefstein (2010), a análise de diferentes eventos de letramento permite perceber que o letramento varia de acordo com o contexto social, podendo os seus participantes estar envolvidos em uma forma e não em outra, apresentando, em função desse aspecto, identidades diferentes, habilidades e envolvimentos em relações sociais diferentes.

Dado o fato de que se vive numa sociedade letrada, tecnologicamente complexa, deve-se falar em pluralidade de práticas de letramento, como sugere Ivanic (1989). As práticas diferem de uma esfera social para outra, de um grupo social para outro. Sob esse enfoque é que se pensou, aqui, nas práticas de letramento na esfera acadêmica, mais especificamente, na modalidade a distância, uma vez que, em termos metodológicos, apresentam características específicas que, de certa forma, se diferenciam das práticas da modalidade presencial. Como exemplo desse aspecto, pode--se mencionar o processo de interação entre os participantes, que se caracteriza pelo aspecto virtual e os usos do escrito que, nessa modalidade de ensino, apresentam diversos formatos, compreendendo tanto o material impresso quanto o eletrônico ou virtual (CD-ROMs, arquivos digitais, softwares, hipertextos, etc.).

É nesse horizonte de reflexões que se pensou em investigar o processo de construção da identidade de estudante como leitor na esfera acadêmica, isto é, investigar como se efetivam as práticas leitoras do Curso de Letras, modalidade a distância. Tais reflexões levaram a perceber a importância de desenvolver atividades de letramento específicas, isto é, atividades que possibilitassem aos participantes, por meio de diferentes usos da escrita, falar sobre as suas práticas leitoras no curso em questão, como também sobre suas experiências leitoras além do âmbito escolar, reportando a outros espaços (família, trabalho) em que se fazem diferentes usos da escrita.

Para tanto, criou-se a sala de leitura virtual, por meio da qual se desenvolveram diversos eventos de letramento: a) questionário, aplicado online, que objetivou levar

4 Street e Lefstein (2010) partem do conceito de "eventos de letramento", cunhado por Shirley Heath (1983), para verificar se há uma padronização dos eventos de letramento nas práticas sociais. 
os participantes a falarem sobre seus perfis socioeconômicos e sobre seus grupos de pertença; b) memoriais, fóruns, diários de leitura, que instigaram as participantes a refletirem sobre si e sobre as próprias experiências de leitura; c) entrevista, realizada face a face, que promoveu oportunidades para as estudantes falarem sobre si e as próprias práticas leitoras. Tais eventos possibilitaram conhecer as práticas de letramento do curso em pauta e, ainda, flagrar, nos discursos das participantes, as maneiras próprias de pensar, falar, agir, de significar, que as identificam enquanto estudantes e leitoras, o que, por conseguinte, evidenciou o processo de construção de suas identidades como leitoras nessa esfera, cujos resultados são apresentados no capítulo 4 da Tese de Doutorado (FONSECA, 2014).

Por fim, conclui-se que os estudos de letramento, na perspectiva ideológica (STREET e LEFSTEIN, 2010; KLEIMAN, 1995, 2008), possibilitam questionar as práticas de letramento excludentes, isto é, aquelas que ignoram os aspectos socioculturais dos contextos de aprendizagem e as práticas de letramento de grupos sociais menos privilegiados; tal perspectiva abre espaço para novos modelos que considerem a pluralidade e a diferença de contextos sociais específicos, entre eles, os letramentos da esfera acadêmica, modalidade a distância, que requerem a observação de diversos aspectos sociais e culturais que medeiam as práticas leitoras desse espaço, dentre os quais se podem mencionar os grupos de pertença dos estudantes, idade, trajetória escolar, tempo para dedicação aos estudos, concepções e finalidades de leitura. De certo modo, tais aspectos podem ser vistos como fundamentais para a compreensão das maneiras como tais estudantes pensam, agem e ressignificam a própria realidade.

Para dialogar com as discussões acerca do letramento ora apresentadas, recorremos a Bartlett e Holland (2002), que nos convidam a pensar na interface entre as práticas de letramento e identidade, levando-nos a entender que o letramento como prática social que compreende os diferentes usos da escrita em contextos específicos está intimamente relacionado com o processo de construção de identidade do estudante, no papel de leitor, uma vez que as atividades de letramento, conforme exposto acima, permitem ao estudante refletir sobre as próprias experiências de leitura e se ressignificar enquanto leitor. Considerando essa interface, aborda-se a seguir o conceito de identidade praticada. 


\section{O conceito de identidade praticada}

A análise do corpus aqui investigado fundamenta-se no conceito de Identidade Praticada proposto por Holland et al. (2010). Os autores pontuam que as identidades são concebidas como produtos históricos, íntimos e públicos, que habitam a interação das práticas sociais. As identidades são vivenciadas, praticadas na atividade, constituindo-se como os meios pelos quais as pessoas desenvolvem novos mundos, novas maneiras de ser e novas identidades, estas situadas e praticadas no curso da interação. Considerando essa linha de pensamento, reportamo-nos à leitura, que, concebida como uma prática social, também se efetiva por meio de atividades socialmente construídas.

Segundo esse modelo teórico, a identidade se constrói na interatividade das práticas sociais. Relativamente à leitura, entende-se que a identidade de estudante, no papel de leitor, se constrói na própria atividade ${ }^{5}$, na interação do processo de ler. Nessa perspectiva, a identidade praticada abrange tanto os aspectos de foro íntimo, privado, quanto os de foro público, isto é, abrange tanto a subjetividade do leitor quanto a coletividade (os aspectos referentes à sua pertença a um grupo de leitores).

Abordamos o conceito de identidade praticada aqui tomando como referência as categorias posicionamento social e posicionamento autoral, as quais se articulam com o objetivo de compreender os aspectos individuais e coletivos que constituem a identidade de estudante, no papel de leitor. Ou seja, essas categorias possibilitam compreender tanto a subjetividade desse sujeito (as características que o identificam enquanto sujeito singular), quanto a coletividade (os aspectos que o identificam em relação à sua filiação a determinado grupo social). Importa esclarecer que a proposição dessas categorias faz-se relevante, uma vez que evidenciam a maneira como o estudante se posiciona em relação a si mesmo e à realidade que o cerca. Esses dois conceitos evidenciam as dimensões subjetiva (o $\mathrm{Eu}$ ) e coletiva (o Outro) que constituem o processo identitário do estudante. $\mathrm{Ou}$ seja, ele se constrói estudante, leitor universitário, na sua interação com o Outro.

Entretanto, ressaltamos que essas duas dimensões não se separam na prática,

5 Entende-se por "atividade" tanto o processo de interação quanto a atividade de leitura em si. 
uma vez que estão imbricadas, uma não existindo sem a outra. Esse aspecto da identidade é abordado por vários autores (CHARTIER, 1999; STREET;LEFSTEIN, 2010; HALL e WOODWARD, 2004; BAKHTIN, 1981), os quais assinalam que a subjetividade se constitui na interface entre o EU e o OUTRO, o que reforça a afirmativa de que essas duas dimensões não se separam; para falar de si, é preciso se referir ao outro.

Porém, neste estudo, faz-se a distinção (subjetividade/coletividade) para fins metodológicos, com o objetivo de demonstrar que a identidade se constrói nessas duas dimensões, segundo as quais se analisam os dados, procurando identificar pistas que revelem ora a subjetividade do participante, ora sua inserção no grupo de estudantes de Letras a distância. Diante disso, passa-se agora à discussão da categoria Posicionamento social.

Aborda-se o posicionamento social segundo as perspectivas teóricas da História Cultural (CHARTIER, 2002) e da Antropologia (HALL; WOODWARD, 2004; HOLLAND et al., 2010; HYLAND, 2012) que assinalam a relação do sujeito com sua posição social ou do sujeito com o discurso, o que corrobora a importância dessa categoria para este estudo, uma vez que ela reflete a maneira como o indivíduo se posiciona, se expressa, se vê em relação à posição que ocupa. Neste trabalho, o posicionamento social reporta à forma como o estudante se representa em relação à leitura, isto é, como ele se vê em relação a esse lugar - "leitor universitário" -, que pressupõe a interação com textos, e modos de ler específicos. Diante disso, pretende-se demonstrar que o posicionamento social emerge no discurso do participante, cujos modos de dizer evidenciam sua subjetividade, sua singularidade em relação às formas como ele se apropria dos objetos de leitura na esfera acadêmica.

Considerando que o osicionamento social está relacionado aos hábitos de ler do participante, recorre-se à noção de habitus (BOURDIEU, 2000), que se mostra importante para o trabalho analítico, visto que enfatiza a relação entre o agente e o conhecimento por ele adquirido. Essa noção, conforme assinala Bourdieu (2000), rompe com o paradigma estruturalista que postulava o agente reduzido ao papel de suporte. Advogando em favor da capacidade criativa do indivíduo, o autor propõe que: 
habitus, como indica a palavra, é um conhecimento adquirido e também um haver, um capital (de um sujeito transcendental da tradição idealista) o habitus, a hexis, indica a disposição incorporada, quase postural -, mas sim o de um agente em ação: tratava-se de chamar atenção para o "primado da razão prática" de que falava Fichte, retornando ao idealismo, como Marx sugeria nas Teses sobre Feuerbach, o "lado ativo" do conhecimento prático que a tradição materialista, sobretudo com a teoria do reflexo, tinha abandonado. (BOURDIEU, 2000, p. 61 - destaques do autor).

Sob esse enfoque, o autor convida-nos a pensar que a noção de habitus remete ao conhecimento adquirido, socialmente construído, isto é, compreende as experiências individuais, adquiridas por meio de um sistema de disposições estruturadas que compõem as experiências práticas de contextos específicos, vivenciadas pelos indivíduos, as quais orientam o seu agir cotidiano. Em outras palavras, tal conceito possibilita apreender no discurso do participante as mudanças ocorridas em suas práticas leitoras, o que reflete o seu posicionamento autoral, a sua forma de pensar e se representar em relação à construção de novos hábitos de leitura. Tomando como referência essa noção, considera-se, aqui, habitus como hábitos, isto é, ações de mudanças empreendidas pelo participante, de forma sistematizada, que revelam o seu agir. Ou seja, a construção de novos saberes, entre eles, novos hábitos de ler, que se afiguram no seu processo de construção identitária, como aspectos que contribuem para a sua filiação no grupo de estudantes universitários, no papel de leitores.

Passa-se agora à categoria Posicionamento autoral, que conforme já anunciado, remete ao aspecto social (dimensão coletiva).

O Posicionamento autoral reporta ao espaço de autoria (HOLLAND et al., 2010; BAKHTIN, 1981) que remete à relação entre o sujeito, o discurso e a sua posição social. De acordo com essa noção, o discurso do indivíduo não é neutro, mas permeado por várias vozes sociais. No que diz respeito às participantes deste estudo, isto quer dizer que seus discursos são marcados por vozes sociais (ideias ou concepções) de outros indivíduos com quem interagem, sejam eles professores, autores, pesquisadores, colegas, disciplinas ou a sociedade, etc., das quais se apropriam para validarem o seu dizer, processo que Holland et al. (2010) denomina de "orquestração de vozes". 
Recorrendo aos dados desta investigação, pode-se citar como exemplo desse aspecto o caso de várias participantes que, ao falarem sobre leitura, exemplificam o seu dizer citando autores da área de estudos, entre eles, Paulo Freire, com o objetivo de usar um argumento de autoridade para atestar, validar o seu dizer. Isso demonstra que o participante reflete em seu discurso diversas vozes sociais que são parafraseadas, orquestradas com o objetivo de fundamentar a sua própria opinião, isto é, construir o seu posicionamento autoral. Daí a importância de considerá-lo como categoria de análise, uma vez que, para falar de si, faz-se necessário referirse ao outro, aos aspectos externos, que constituem a identidade e emergem no discurso do participante.

"Posicionamento autoral" diz respeito à interação do participante com o Outro (professores, autores, colegas). A esse respeito, Chartier (1999; 2002), Chartier et al. (2001) e Hyland (2012) assinalam a relação do sujeito (leitor) com a sua comunidade ou grupo de pertença. Os autores enfatizam que a subjetividade do leitor é marcada por traços de sua coletividade. Ou seja, o leitor traz em seu discurso elementos linguísticos (escolhas linguísticas) que o identificam como participante de um determinado grupo. Por exemplo, o estudante de letras apresenta modos de dizer específicos que o indexam, o identificam como tal, da mesma forma que o biólogo, o psicólogo, o médico ou o religioso, entre outros.

\section{O Percurso metodológico}

Este estudo baseou-se na "Etnografia educacional” (ANDRÉ, 2012; FRITZEN; LUCENA, 2012; BUENO, 2007), configurando-se como estudo de caso. A investigação iniciou-se com um grupo de 27 estudantes do Curso de Letras/ Português, modalidade a distância. Porém, para fins de análise, selecionamos desse grupo apenas 8 estudantes, do sexo feminino, que participaram regularmente de todas as atividades propostas pela pesquisa. Esse recorte fez-se necessário em função de conseguirmos uma unidade, aspecto considerado importante para um estudo de caso, conforme salienta André (2012).

A respeito do instrumento de pesquisa, selecionamos para as discussões deste artigo, os memoriais. Para aplicação desse instrumento foi criada uma sala de 
leitura, em ambiente virtual - Plataforma Moodle/Virtualmontes (cf. FONSECA, 2014). Essa sala, criada pela pesquisadora, configurou-se como um ambiente de atividades de leitura multifacetado, que possibilitou o acesso a diversos objetos de leitura (textos suplementares, vídeos, textos das próprias participantes) e a realização de atividades de leituras variadas, entre elas, os memoriais. Tais procedimentos promoveram a interação entre as participantes, suscitaram reflexões sobre as próprias práticas leitoras, além de possibilitar uma maior aproximação entre elas e a pesquisadora.

A produção de um memorial, por exemplo, possibilitou coletar dados sobre suas histórias de leitura. Nesse sentido, os memoriais configuraram-se como o produto de uma atividade de letramento que teve como objetivo principal conduzir as participantes à reflexão sobre suas experiências de leitura, por meio da ação de recordar ${ }^{6}$. Essa atividade fundamentou-se no conceito de memorial, postulado por Silva (2010). Segundo a autora,

as narrativas memoralísticas, o trabalho de recordação é uma espécie de trabalho de objetivação, mediado pela interseção de histórias pessoais, coletivas e sociais. É nesse sentido que o indivíduo é visto como sujeito que interpreta e significa o mundo, constrói para ele uma compreensão individual, povoada por sentimentos, emoções, impressões, oriundas de seu universo sociocultural. Em outras palavras, os memoriais consistem em um trabalho de recordação das experiências individuais que, trazidas pelos estudantes para a construção de seu discurso, encarnam as tonalidades sociais, históricas, culturais e afetivas, fundadas por uma carga axiológica. (SILVA, 2010, p. 6).

Tendo-se em vista a noção apresentada, entende-se que os memoriais se constituíram como ações discursivas importantes para este estudo, uma vez que implicam, conforme pontua Silva (2010), um trabalho de recordação das experiências individuais. Nesse sentido, as participantes, por meio dos memoriais, recordaram e refletiram sobre as próprias experiências de leitura, construindo um discurso encarnado dos aspectos sociais, históricos e culturais que as constituem. Esses aspectos afiguram-se como essenciais para este estudo, uma vez que nos

6 Para maiores detalhes a respeito da descrição dos dados dos memoriais, ver o Capítulo 4 (FONSECA, 2014). 
possibilitaram apreender aspectos relativos às dimensões subjetiva e coletiva que compõem suas identidades de leitoras.

Considerando o quadro analítico apresentado, passa- se agora à interpretação dos dados, iniciando pela categoria "Posicionamento social".

\section{A emergência do posicionamento social em memoriais}

Para demonstrar o posicionamento social do grupo investigado, abordou-se a sua emergência em relação a dois grupos sociais a "famíli"a e a "graduação". No que diz respeito à família, observou-se que as participantes, para construírem suas identidades como leitoras, referem-se à família, como um dos grupos de pertença que favorece ou não a formação do hábito de ler. Isso se evidencia por meio da referência às práticas leitoras dos membros familiares, que compreende tanto sua ausência quanto sua efetivação. A maioria das participantes $(50 \%)$ constrói sua identidade referindo-se à ausência das práticas leitoras no seio familiar. Para ilustrar esse posicionamento, cita-se a declaração da estudante P04, que afirma:

(2) Sou P04 tenho 26 anos e refletir sobre minhas experiências de leitura me levam a constatar que deveria ter lido muito mais desde sempre. Durante meu período de infância não me lembro de leituras que tenha feito; sei que era boa aluna e fui alfabetizada com facilidade, mas a minha rotina em casa naquela época não tinha foco na leitura longe disso. (P04 - Memorial)

Aqui, a participante (P04) anuncia uma identidade de estudante, no papel de não leitora, por meio da referência à rotina familiar que se caracteriza pela ausência do hábito de ler. Isso se confirma pelo uso dos verbos "refletir" e "constatar", os quais demonstram a consciência da participante em relação a uma formação de leitora insatisfatória, que a leva a concluir que "deveria ter lido muito mais desde sempre". Esse dado corrobora os estudos de Holland et al. (2010) e Chartier (1999), uma vez que a participante constrói sua identidade por meio de sua identificação com seu grupo de pertença, isto é, ela se posiciona como não leitora em função de pertencer a um grupo de não leitores, o que demonstra que possui 
uma subjetividade marcada por traços desse grupo (entre eles, a falta do hábito de ler), os quais emergem em seu discurso na referência à ausência de leitura na infância e na rotina da casa, conforme demonstram os enunciados: "Durante meu período de infância não me lembro de leituras que tenha feito; sei que era boa aluna e fui alfabetizada com facilidade, mas a minha rotina em casa naquela época não tinha foco na leitura longe disso".

Por outro lado, algumas estudantes (P01 e P07) anunciam a construção de uma identidade como leitoras em razão de pertencerem a um grupo familiar que se caracteriza pela presença de membros leitores, como a mãe ou a irmã. Para ilustrar esse posicionamento, cita-se a declaração de P01 (Excerto 2):

(2) Não sei ao certo quando comecei a ler corretamente, mas me recordo de ter as palavras como parte da família, minha mãe era e ainda é professora de português. (P01 - Memorial)

Aqui, a participante (P01) constrói sua identidade como leitora pela referência às "palavras", ou seja, ao acesso ao escrito no âmbito familiar, além da referência à mãe, professora de Português, portanto, leitora, o que confirma que ela se posiciona como leitora em razão de se identificar com seus familiares, considerados leitores.

Conforme anunciado, o "Posicionamento social" também emerge no discurso das participantes em relação à sua filiação ao grupo social "Graduação" (Estudantes do Curso de Letras a distância). Nesse caso, elas constroem suas identidades mediante a referência a três aspectos que envolvem o âmbito acadêmico: o curso em si (que abrange atividades, modos de ler, gestos de leitura, objetos de leitura, autores e colegas), a mudança de hábitos e agência.

A maioria das participantes (87\%) constrói suas identidades de estudantes, no papel de leitoras, reportando-se à sua pertença à graduação, que se constitui como um grupo social com práticas leitoras específicas. Isso emerge em seus discursos mediante a referência que fazem aos aspectos (disciplinas, atividades, modos de ler, gestos de leitura, objetos de leitura, autores e colegas) que compõem as práticas leitoras do Curso de Letras a Distância. Para demonstrar esse fato, apresenta-se, a seguir, o depoimento da participante P01: 
(1) Confesso não ser muito fã de textos científicos dá preguiça só de pensar, que os meus professores não me ouçam, mas gosto de ler sem obrigação, sem ter que fazer um resumo crítico, com exceção do livro José Saramago, Caim fiquei intrigada com a história, me perdi no real e no imaginário, gostei bastante. (P01)

Os dados evidenciam que a estudante (P01) vai construindo sua identidade como leitoras na esfera acadêmica por meio da caracterização das práticas leitoras desse espaço que se efetivam mediante a referência aos aspectos do curso, entre eles: a) objetos de leitura específicos do curso (textos científicos, obras literárias com seus respectivos autores; b) atividades de leitura propostas pelo curso (resumo crítico); c) gestos de leitura (preguiça, obrigação). Isso indica que a filiação ao grupo de leitores acadêmicos pressupõe práticas leitoras específicas, realizadas com propósitos definidos, como, por exemplo, ler para resumir.

Tais aspectos demandam, por parte das estudantes, ações cognitivas mais complexas, além do gerenciamento de novos modos de dizer, aspectos que podem causar ao estudante reações de estranhamento ou cansaço em razão da atividade de leitura em si ou da pouca experiência com esse tipo de leitura. Isso se evidencia no discurso da participante (P01) que, para se construir leitora nesse espaço, faz referência às reações (preguiça, falta de prazer, obrigação) decorrentes da leitura dos textos acadêmicos, que aqui são concebidas como "gestos de leitura". Adotouse essa concepção tomando como referência os conceitos de gestos de leitura ${ }^{7}$ postulados por Chartier (1999), Barthes e Havas (1987) e Certeau (1998). Como já afirmado aqui, os gestos de leitura marcam a subjetividade das participantes, uma vez que refletem suas reações em relação às práticas leitoras na universidade. Nesse sentido, esses gestos compreendem tanto as reações positivas (prazer, alegria, intimidade) quanto a negativas (falta de prazer, cansaço, preguiça, obrigação, etc.).

Conforme demonstrado, a participante P01 revela em seu dizer gestos de leitura (preguiça, falta de prazer, obrigação) que marcam sua subjetividade, uma vez que, por meio desses gestos, ela nega o gosto pelas leituras acadêmicas. Ao fazer isso, ela se posiciona como leitora em relação ao curso, ao grupo de estudantes de

7 Alguns autores (CHARTIER, 1999; BARTHES, 1987) concebem os gestos de leitura como movimentos corporais empreendidos pelo leitor durante a leitura como, por exemplo, o movimento dos olhos, dos lábios, do aparelho oral, além de movimentos como sentar, levantar, deitar. Para Certeau (2008), os gestos compreendem ainda os balbucios, resmungos, tics ou outros ruídos. 
Letras, assumindo uma condição de estudante que pressupõe responsabilidades, obrigações. Entretanto, ao mesmo tempo em que assume essa condição, ela nega esse lugar de leitora mediante a rejeição aos objetos de leitura e aos modos de ler acadêmicos, o que se confirma pelo uso de expressões como "não ser muito fã", “dá preguiça só de pensar", "que os professores não me ouçam, gosto de ler sem obrigação", conforme demonstra o excerto 1 .

Porém, ao negar essa condição de leitora na esfera acadêmica, a participante assume outro lugar, constrói uma identidade de estudante que gosta de ler sem obrigação. Aqui, ela se posiciona em relação ao grupo, deixando emergir uma voz que anuncia o gosto pela leitura de fruição ou leitura do prazer em detrimento da leitura intensiva, oferecida e promovida pela universidade. Isto se confirma pelo emprego dos elementos verbais "confesso" e "dá" ("Confesso não ser muito fã de textos científicos; dá preguiça só de pensar" - P01) que trazem à cena algo que não poderia ser dito, sugerindo a existência de uma representação de leitura divergente das representações do âmbito acadêmico, fato que também se faz notar na expressão "que os professores não me ouçam".

Outra categoria que contribui para a emergência do posicionamento das participantes em relação ao grupo Graduação (Estudantes de Letras) é Hábitos. Tendo em vista o conceito de Habitus de Bourdieu (2000), que remete ao conhecimento adquirido e à agência do sujeito, procura-se apreender, aqui, os hábitos, isto é, as ações de mudança que marcam o agir das participantes em relação ao próprio processo de construção da identidade de leitoras, o que será feito mediante a apresentação dos traços linguísticos (dêiticos temporais e indicadores de agência). Para ilustrar esse dado, cita-se, primeiramente, a declaração da participante P02:

(2) Nunca tive o hábito de ler, ao longo da minha vida passei por muitas dificuldades, não sabia que uma boa leitura tem o poder de transformar e de modificar uma pessoa. Hoje tenho a oportunidade de ler bons livros. Estou pegando gosto pela leitura (P02).

Aqui, a participante (P02) utiliza-se dos dêiticos temporais (nunca, hoje) para fazer referência a dois momentos de sua trajetória escolar, antes da graduação e durante a graduação. Esses dois momentos são marcados em seu discurso por 
meio de uma relação discursiva de oposições (faltar X ter). Ou seja, o momento (antes da graduação) é marcado pela falta de oportunidades ("ao longo da minha vida passei por muitas dificuldades"), e de conhecimentos ("não sabia que uma boa leitura tem o poder de transformar e de modificar uma pessoa"). Observa-se, aqui, que a participante, ao falar de si, reporta-se aos aspectos históricos e sociais que marcam sua história de leitora. Isso confirma os estudos de Chartier (1999) a respeito dos aspectos sociais e históricos que constituem o sujeito, uma vez que a estudante se posiciona como uma leitora que em determinado momento de sua história não teve oportunidades de praticar a leitura em razão das dificuldades financeiras.

O outro momento (durante a graduação), introduzido pelo uso do dêitico "hoje", permite a participante reportar-se ao momento atual, a graduação. Essa fase, diferentemente da anterior, caracteriza-se pela construção de conhecimentos ("a leitura transforma e modifica uma pessoa") e o surgimento de oportunidades de ler ("Hoje tenho a oportunidade de ler bons livros"). Observa-se, aqui, a emergência de uma identidade de leitora em construção, que está sendo formada, constituindose ao longo da graduação, haja vista que agora a participante se posiciona como uma estudante que conhece o poder transformador da leitura e tem oportunidade de ler bons livros. Isso sugere o caráter mutável da identidade praticada que se constrói em situações específicas, na própria prática da leitura. E ainda indica o agir da participante por meio da mudança de seu comportamento (construção de uma concepção de leitura transformadora) e no desenvolvimento do hábito de ler, como ela própria afirma "Estou pegando o gosto pela leitura".

Por fim, observou-se que para construírem suas identidades de estudantes, leitoras universitárias, as participantes reportam aos grupos sociais família e Graduação (Estudantes de Letras), por meio, dos quais, ora se posicionam como leitoras ou nãoleitoras, ao se identificarem ou não com os membros familiares. Ora, se posicionam como leitoras ou leitoras em formação em razão de praticarem a leitura como obrigação ou como um novo hábito que está sendo adotado em razão da filiação ao grupo de estudantes de Letras.

\section{A emergência do posicionamento autoral}

Como dito, o posicionamento autoral remete ao espaço de autoria em que ocorre a orquestração de vozes (cf. HOLLAND et al., 2010; BAKHTIN, 1981). Ou seja, para falar de si, enquanto sujeito leitor, as participantes fazem referência ao 
OUTRO, à coletividade, aos aspectos externos que concorrem para a consolidação de sua subjetividade, sua identidade de leitoras. Nesse sentido, as participantes gerenciam as diversas vozes que compõem esse espaço para construir seu discurso, seu posicionamento autoral a respeito da leitura.

Observa-se que apenas a minoria das participantes (26\%) evidenciou em seu dizer (memoriais) um posicionamento autoral em relação à leitura, que se ilustra por meio do seguinte depoimento:

(3) Enfim, constatei que meu prazer na leitura ultimamente tem sido ler para meu filho. Não é que os outros tipos de leitura não me agradem, o que acontece é que meu tempo gasto para ler tem sido gasto com as leituras obrigatórias da faculdade. Leio muitas apostilas e também livros e arquivos digitais para aprender melhor os conteúdos do meu curso. Assim me falta tempo para ler algo que seja escolha minha, que me agrade e me dê prazer. Felizmente tenho a oportunidade de ler com prazer, amor e carinho junto com o meu filho. (P04)

O excerto 3 revela que a participante P04 constrói seu posicionamento autoral mediante a referenciação a dois espaços coletivos: a escola e a família. Com relação à escola, ela traz vozes que remetem a dois tipos de leitura, a leitura do prazer (ou fruição) e a leitura obrigatória (ou de instrução). Além desses aspectos, outros são trazidos à cena como, por exemplo, os objetos de leitura da esfera acadêmica (apostilas, livros e arquivos digitais). Com relação à família, ela se refere ao filho, posicionando-se como leitora que se preocupa com a formação do hábito de ler dele.

A participante $\mathrm{P} 04$ constrói em seu discurso uma identidade de leitora que gosta de ler por prazer. Isso se evidencia pelo uso do verbo "constatar" no enunciado "Enfim, constatei que meu prazer na leitura ultimamente tem sido ler para meu filho", em que ela gerencia duas vozes; uma voz que é singular, particular, que remete à própria escolha dos objetos de leitura e à leitura por prazer e, outra, advinda da graduação, que se reporta aos objetos de leitura da esfera acadêmica e às leituras obrigatórias, realizadas em função do curso. Aqui, o verbo constatar indica que o posicionamento autoral da participante se dá na confrontação de dois tipos de leitura (prazer X obrigação) que lhe permite emitir uma opinião a respeito do que gosta de ler e se posicionar em favor da leitura de fruição, como ela própria 
afirma "Felizmente tenho a oportunidade de ler com prazer, amor e carinho junto com o meu filho". Esse posicionamento é reafirmado pela estudante, ao explicar "Assim me falta tempo para ler algo que seja escolha minha, que me agrade e me dê prazer", evidenciando que o hábito de ler pressupõe as próprias escolhas e o prazer, além de deixar antever o caráter obrigatório das leituras impostas pelo curso.

Por fim, conclui-se que a emergência do posicionamento autoral nos memoriais se evidencia na referência a dois espaços: a família e a escola em que as vozes referentes às leituras (prazer/obrigação) são orquestradas para a construção da identidade de estudantes, no papel de leitores, favoráveis à leitura por prazer.

No que diz respeito ao processo identitário, conclui-se que a identidade de estudantes, no papel de leitores, em memorias se constrói na relação dos estudantes com dois grupos sociais (família e curso). Em relação à família, a maioria das participantes se posiciona como não leitora, identificando-se como tal na relação com os familiares não leitores. Algumas (13\%), entretanto, se posicionam como leitoras por se identificarem com os membros familiares, considerados leitores. Esses posicionamentos emergiram em um processo de referenciação que apresentou como principais traços linguísticos a descrição das práticas leitoras familiares e a reflexão sobre si. Tais posicionamentos sugerem o caráter plástico e mutável da identidade, uma vez que as estudantes ora se posicionam como leitoras, ora como não leitoras.

Em relação à graduação (Curso de Letras a distância), observa-se que todo o grupo revela uma identidade de estudantes como leitoras em construção que se revela na referência às práticas leitoras da esfera acadêmica, à mudança dos hábitos de leitura em função da filiação ao Curso de Letras a distância. E ainda, na assunção de um posicionamento autoral que emerge por meio de uma orquestração de vozes advindas dos dois grupos de pertença, a família e a graduação.

\section{Considerações finais}

As discussões apresentadas neste artigo partiram das noções de letramento ideológico e de identidade praticada que possibilitaram compreender a leitura 
enquanto prática social que se efetiva na interação e em contextos de usos da leitura e escrita específicos. Segundo tais noções, observamos que a identidade de estudante, no papel de leitor no âmbito acadêmico se constrói mediante os posicionamentos social e autoral. O posicionamento social possibilitou-nos entender que a assunção da posição de estudante de Letras, modalidade a distância, de leitor universitário, implicam a participação efetiva nesse grupo, a interação com os objetos de leitura e com os demais participantes (colegas, professores, leitores, autores) desse espaço. Isto implica, ainda, adotar, em certa medida, as características das práticas leitoras desse grupo, que passam a constituir a subjetividade desse leitor, emergindo em seu discurso, nos seus modos de dizer, contribuindo para identificá-lo enquanto sujeito-leitor do âmbito acadêmico. Esse posicionamento revelou o caráter plástico da identidade, uma vez que, dependendo do grupo social (família ou graduação), o estudante ora se posiciona como leitor, não leitor ou leitor em formação. O Posicionamento autoral revelou que as práticas leitoras desse grupo caracterizam-se pelas concepções de leitura (obrigação/prazer), evidenciando que a leitura na universidade é praticada para atender as exigências acadêmicas, apresentando um caráter obrigatório, aspecto que contradiz as concepções de leitura de alguns participantes que se posicionam favoravelmente a prática da leitura por prazer.

Esse aspecto identitário revelado nos memoriais aponta a necessidade de novas pesquisas que busquem investigar mais especificamente as causas das concepções de leitura evidenciadas neste estudo. E, ainda, a necessidade de repensar as práticas leitoras no âmbito acadêmico, modalidade a distância, a fim de se promoverem ações que visem a despertar o gosto e o prazer pela leitura na universidade. 


\title{
Identity construction: the emergence of social and authoral positionings in memoirs
}

\begin{abstract}
This paper aims to discuss the construction process of students' identity as readers, in memoirs under the perspective of Ideological Literacy and Identity in practice. Through an ethnographic case study, it was observed that the identity process of the students of a Language and Literature graduate course, distance modality, emerge in memoirs through the subjective and collective interface, in which it is possible to note the students' social and authorial positioning through which they identify themselves as readers of the academic sphere. The results reveal the plastic feature of the identity which varies according to the students' social group. The results still show that the reading practices of the interviewed group are marked by some reading gestures such as obligation and pleasure whose contradictions demonstrate that the students' reading conceptions which are concerned to the academy and other social groups, such as family, are divergent.
\end{abstract}

Keywords: Literacy. Reading. Identity. Memoirs.

Referências

ANDRÉ, Marli Eliza Dalmazo Afonso de. Etnografia da prática escolar. 18. ed. Campinas, SP: Papirus, 2012.

BAKHTIN, Mikhail M. The dialogic imagination: for essays by M. M. Bakhtin. Ed. Michael Holquist. Tradução de Caryl Emerson e Michael Holquist. Austin: university of Texas Press, 1981.

BARTHES, Roland; HAVAS, Roland. Leitura. In: ENCICLOPÉDIA Einaudi. Lisboa: Imprensa Nacional, Casa da Moeda, 1987. V. 11, p. 184-206.

BARTLETT, Lesley; Holland, D. Theorizing the space of literacy practices. Ways of knowing journal. v. 2, n.1, p. 10-22, 2002.

BARTON, David.; HAMILTON, Mary. Literacy practices. In: STREET, Brian V.; LEFSTEIN, Adam. Literacy: an advanced resource book. New York: Routledge, 2010. p. $142-149$

BARTON, David; HAMILTON, Mary; IVANIC, Roz. Situated Literacies: Reading and Writing in Context. London: Routledge, 2000. 
BOURDIEU, Pierre. O poder simbólico. Tradução de Fernando Tomaz. 3. ed. Rio de Janeiro: Bertrand Brasil, 2000.

BUENO, Belmira Oliveira. Entre a Antropologia e a História: uma perspectiva para a etnografia educacional. Perspectiva. Florianópolis, v. 25, n. 2, p. 471-501, jul/dez. 2007.

CERTEAU, Michel de. A invenção do cotidiano: artes de fazer. Tradução de Ephraim Ferreira Alves. Petrópolis: Vozes, 1998.

HARTIER, Roger et al. (Org.). Práticas da leitura. Tradução de Cristiane Nascimento. 2. ed. São Paulo: Estação Liberdade, 2001.

CHARTIER, Roger. A aventura do livro: do leitor ao navegador. São Paulo: Editora UNESP/Imprensa Oficial do Estado de São Paulo, 1999.

CHARTIER, Roger. A história cultural: entre práticas e representações. 2. ed. Rio de Janeiro: Difel, 2002.

FONSECA, Hejaine de Oliveira. Um estudo sobre a construção da identidade de estudantes, no papel de leitores, em um Curso de Letras a distância. 2014. 138 p. Tese (Doutorado em Letras. Área de concentração: Linguística e Língua Portuguesa) - Programa de Pós-Graduação em Letras, Faculdade de Letras,Pontifícia Universidade Católica de Minas Gerais, Belo Horizonte, 2014.

FRITZEN, Maristela Pereira; LUCENA, Maria Inéz Probst. O olhar da etnografia em contextos educacionais: interpretando práticas de linguagem. Blumenau: Edifurg, 2012.

HALL, Stuart; WOODWARD, Kathryn. Identidade e diferença: a perspective dos estudos culturais. Tradução: Tomaz Tadeu da Silva. 3ed. Petrópolis: Vozes, 2004.

HEATH, Shirley Brice. Ways with words: language, life and work in communities and classrooms. Cambridge: Cambridge University Press, 1983.

HOLLAND, Dorothy et al. Identity and agency in cultural worlds. Cambridge: Harvard University Press, 2010.

HYLAND, Ken. Disciplinary identities: individuality and community in academic discourse. Cambridge University Press, 2012.

IVANIC, Roz. Writing and identity: The Discoursal Construction of Identity in Academic Writing. Philadelphia: John Benjamins, 1989. v. 5. 
KLEIMAN, Angela. Bustos. (Org.). Os significados do letramento: uma nova perspectiva sobre a prática social da escrita. Campinas, SP: Mercado de Letras, 1995.

KLEIMAN, Angela. Bustos. A construção de identidades em sala de aula: um enfoque interacional. In: SIGNORINI, Inês (Org.). Língua(gem) e identidade: elementos para uma discussão no campo aplicado. Campinas, SP: Mercado de Letras, 2008b. p. 267--302.

SILVA, Jane Quintiliano Guimarães. A identidade praticada dos leitores na esfera acadêmica. Proposta de estágio de pós-doutorado no Teachers College, Columbia University, NY/USA. Belo Horizonte: Puc Minas, 2011.

SILVA, Jane Quintiliano Guimarães. O memorial no espaço da formação acadêmica: (re)construção do vivido e da identidade. Revista perspectiva. UFRS. v. 28, n. 2, 2010.

STREET, Brian V. Literacy in theory and practice. Cambridge: Cambridge University Press, 1984.

STREET, Brian V. Social literacies: critical approaches to literacy in development, ethnography, and education. London/New York: Longman, 1995.

STREET, Brian V.; LEFSTEIN, Adam. Literacy: an advanced resource book. New York: Routledge, 2010. 
